ties. Notable progress has been made in the Depart. ment of Embryology in the analysis of the control of sex differentiation in the embryo by the action of sexgland hormones; and a long-term study of the blood flow through the placenta, first in monkeys bred for the purpose, and afterwards on human placentas, points to physiological factors - that is to say, differences in blood pressure between the maternal arterial and venous blood and the blood within the placentaas the chief directive agency of the maternal placental circulation, assisted by anatomical features of placental structure. Experiments on pregnant rhesus monkeys suggest that sugar metabolism in the primate placenta is not like that in sheep, at least with respect to glucose and fructose. The Department of Archæology continued its researches dealing with the preconquest history of Yucatan.

\section{RELATIONSHIP OF SCIENCE AND RELIGION}

$I^{\mathrm{N}}$

his Rede Lecture for 1954 on "Science and Religion : a Changing Relationship", which has now been published*, Prof. C. A. Coulson, pointing out that Nature (by which he means the totality of our environment) and man are central both to science and religion, maintains that the division of our experiences into those labelled scientific and those labelled religious is wholly unsatisfactory and false to the true character both of science and religion. Science claims to give an account of all our environment, and he believes that the limits of science are only those which are presented by the words : if a question about Nature can be posed in scientific terms, then ultimately it will be susceptible of $a_{0}$ scientific answer. In remarking that every scientific law is a new imaginative conception, Prof. Coulson suggests that, like the artist, the poet and the saint, the scientist is making sense out of that part of his experience which appears most amenable to his own selective understanding; he is looking for a pattern within them which will satisfy him as reasonable and consistent. Science is one kind of pattern, art is another.

Our loss of immediacy in our relation to Nature has, Prof. Coulson thinks, increased rather than diminished the contrast between conventional science and religion. Among the scientists of to-day there are respect and excitement, sometimes astonishment, but all too seldom reverence; and if we could recognize that man's total response to Nature must include not merely the making of a pattern that may be called true but also the recognition that God is mediated to him both in the experience and in the pattern, science would be recognized as one of the languages in which God is revealed, and the work of scientists would be seen as part of God's work. The sense of immediacy, which has largely been lost in modern scientific study, would be rediscovered. Our approach to the study of man is also changing, and here Prof. Coulson thinks science can help religion by forcing us to see and understand the sacramental value of Nature and the wholeness and unity of things. Science is also a powerful and insistent reminder of the worth of reason at a time when men's faith in the virtues of reason is wavering. A

* Science and Religion : a Changing Relationship. (Rede Lecture for 1954.) Pp. 36. By Prof. C. A. Coulson. (Cambridge: At the University Press, 1955.) 2s. $6 d$. net. faith in rationality is central to the Christian tradition at its finest. Science is also affecting our view of the role of men within the whole pattern of Nature. Men and Nature are inextricably mixed, and Prof. Coulson believes that science has something to say about the very structure of human fulfilment, for which Christians have greater reasons for being grateful than they sometimes admit. There is a liberating quality about scientific thinking to-day, and yet a humility, which seems to him to augur well for a future complementary relation between science and religion.

In its methods of working, in its dependence upon the assumption of a spiritual wholeness about life, in its insistence upon the richness and variety of experience, and the inter-relatedness of all things within the role of a person, continued Prof. Coulson, the changing pattern of science has come back to something more like harmony with the Christian faith. In that new harmony there are new notes which would never have been sounded but for the patience, the integrity and the creative imagination of men of science. Lastly, all scientific beliefs are experimental in character, and the concepts of science acquire their validity only in experience. This is also true of the Christian faith, and it is one more debt which religion owes to science.

\section{BURSTS OF RADIO EMISSION}

R D. DAVIES has published a paper entitled R. "An Analysis of Bursts of Solar Radio Emission and their Association with Solar and Terrestrial Phenomena" (Mon. Not. Roy. Astro. Soc., 114, 1; 1954), which presents a detailed analysis of bursts of radio emission recorded at the Radiophysics Laboratory, Sydney, during January 1950-June 1951. This analysis includes a detailed study of the correlation of bursts with flares, sunspots, ionospheric fade-outs and magnetic crochets. While attempts to draw physical conclusions from the analysis have not been made in most cases, nevertheless certain results of immediate interest are briefly discussed. The radio data were obtained mostly from records at $200,600,1,200,3,000$ and $9,400 \mathrm{Mc} / \mathrm{s}$., and in the latter part of the analysis these were extended to 62 and $98 \mathrm{Mc} / \mathrm{s}$. All these came from the records taken at the Radiophysics Laboratory, Sydney, except the first, which came from records from the Commonwealth Observatory, Mt. Stromlo.

The analysis-in two parts-includes a number of histograms, and shows that many of the properties of bursts change with frequency (a burst is defined as "any clear-cut solar radio emission rising above the daily level"). A characteristic of bursts is their 'jaggedness', that is, short-duration rises and falls in intensity, and the degree of jaggedness decreases with increasing frequency. Tables, figures and histograms show that there are many interesting relations between the number of bursts and their frequencies, and also between bursts and sunspots, flares, fade-outs and crochets. As the frequency of bursts rises from 600 to $9,400 \mathrm{Mc}$./s., their average number per hour diminishes from 0.10 to 0.04 , and the average interval between the bursts increases from 10 to $26 \mathrm{hr}$. A number of figures shows the distribution of the lifetime of the bursts at the different frequencies, the distribution of their decay times, the distribution of their intensities, etc. 